\title{
PENGEMBANGAN KAWASAN EKOWISATA MANGROVE DI PANTAI LABU SAWO, DESA PENYARING, SUMBAWA
}

\section{MANGROVE ECOTOURISM DEVELOPMENT IN LABU BAJO BEACH, PENJARINGAN VILLAGE OF SUMBAWA DISTRICT}

\author{
Baiq Hiilda Astriana*), Chandrika Eka Larasati, Ayu Adhita Damayanti \\ Program Studi IImu Kelautan, Universitas Mataram \\ Jalan Pendidikan Nomor 37, Kota Mataram, Provinsi NTB, 83115 \\ Alamat korespondensi : arda804@yahoo.co.id
}

(Tanggal Submission: 15 Januari 2020, Tanggal Accepted: 13 April 2020)

\begin{abstract}
ABSTRAK
Kegiatan pengabdian ini bertujuan untuk mengetahui potensi pengembangan kawasan ekowisata mangrove serta memberikan pemahaman kepada kelompok masyarakat mengenai pengelolaan kawasan ekowisata mangrove yang saat ini telah dikembangkan di Pantai Labu Sawo, Desa Penyaring, Kecamatan Moyo Utara, Kabupaten Sumbawa. Dusun Labu Sawo memiliki pantai yang sangat indah dan termasuk dalam Kawasan Strategis Cepat Tumbuh Samota. Keunggulan lain yang dimiliki kawasan ini adalah vegetasi mangrove yang masih rapat dan alami. Pengembangan kawasan ekowisata hutan mangrove telah dilakukan oleh masyarakat melalui Kelompok Sadar Wisata (POKDARWIS) Labu Sawo. Walaupun demikian, pengelolaan ini belum maksimal karena kurangnya informasi yang dimiliki oleh kelompok tersebut mengenai potensi apa saja yang dapat dikembangkan di kawasan mangrove untuk meningkatkan kesejahteraan masyarakat sekitar. Melalui kegiatan penyuluhan ini, beberapa potensi yang dimiliki oleh Dusun Labu Sawo berhasil diidentifikasi. Hasil pembobotan potensi yang dilakukan menunjukkan bahwa kawasan ini sangat layak (72,8\%) untuk dikembangkan dan dikelola menjadi kawasan ekowisata. Selain itu, diskusi dengan masyarakat setempat juga menunjukkan bahwa potensi-potensi yang ada memang belum dapat dikembangkan lebih jauh. Dengan demikian, masih diperlukan pelatihan-pelatihan terkait untuk meningkatkan jumlah SDM berkualitas serta kegiatan pendampingan masyarakat untuk pengembangan kawasan ekowisata sangat dibutuhkan bagi kawasan ini.
\end{abstract}

Kata kunci: Ekowisata, Mangrove, Labu Sawo, Sumbawa

\section{PENDAHULUAN}

Ekosistem mangrove merupakan salah satu ekosistem yang memiliki fungsi ekologis yang sangat penting di kawasan pesisir dan pantai. Beberapa di antaranya adalah sebagai pelindung dari abrasi/erosi, gelombang atau angin kencang, pengendali instrusi air laut, dan habitat berbagai jenis fauna. Selain itu, kawasan mangrove dijadikan tempat mencari makan, memijah dan berkembang biak berbagai jenis ikan dan udang (Halidah et al., 2008; Umayah et al., 2016).
Pemanfaatan ekosistem magrove juga dilakukan untuk pemenuhan kebutuhan harian penduduk pesisir. Keberadaan beberapa jenis kerang dan kepiting yang mendiami lokasi ini menjadi sumber pangan dan keuangan masyarakat karena selain untuk dikonsumsi kerang dan kepiting juga menjadi komoditas perdagangan. Disamping itu, beberapa jenis mangrove dimanfaatkan sebagai bahan bangunan dan kayu bakar serta kebutuhan lainnya bagi masyarakat di kawasan pesisir. Aktivitas-aktivitas tersebut merupakan ancaman bagi keberadaan ekosistem 
mangrove di beberapa wilayah di Kabupaten Sumbawa.

Paradigma pencegahan dan pengendalian kerusakan hutan saat ini dilakukan dengan menyelaraskan pemanfaatan dengan perlindungan kawasan hutan. Salah satu bentuk nyata upaya tersebut dilakukan dalam bentuk pemanfaatan ekosistem mangrove menjadi lokasi wisata atau ekowisata, dimana ekosistem mangrove dimanfaatkan menjadi objek wisata tanpa aktivitas eksploitasi terhadap sumber daya kayu dihutannya. Sebagaimana diketahui bahwa ekowisata adalah perjalanan wisata ke wilayah wilayah alami dalam rangka mengkonservasi atau menyelamatkan lingkungan dan memberi penghidupan penduduk local (TIES, 1991).

Lokasi hutan mangrove yang saat ini sedang dikembangkan menjadi kawasan ekowisata mangrove di Kabupaten Sumbawa adalah hutan mengrove Labu Sawo yang secara administratif terletak di Desa Penyaring, Kecamatan Moyo Utara, Kabupaten Sumbawa. Pengembangan kawasan wisata hutan mengrove ini dilakukan oleh masyarakat melalui Kelompok Sadar Wisata (POKDARWIS). Keberadaan wisata mengrove diharapkan mampu mendorong pertumbuhan mikro ekonomi melalui pengembangan beberapa usaha seperti penyediaan trasportasi, makanan, dan lainnya. Kelompok sadar wisata merupakan gabungan masyarakat yang secara latar belakang pendidikan tidak memiliki pemahaman yang kuat terhadap ekosistem mangrove sehingga pengelolaan kawasan ekowisata mangrove ini belum dapat dilakukan secara maksimal.

Oleh karena itu, upaya peningkatan pengetahuan kelompok terhadap ekosistem mengrove serta potensi-potensi yang dapat dikembangkan penting untuk dilakukan agar optimalisasi pemanfaatan mangrove sebagai kawasan wisata dapat dilakukan dengan baik. Hal ini akan mendukung keberlanjutan ekowisata mengrove sebagai salah satu upaya perlindungan ekossistem mangrove berbasis peningkatan ekonomi masyarakat lokal.

\section{METODE KEGIATAN}

Kegiatan ini dibagi dalam beberapa tahap kegiatan yaitu: Survei Lapangan, Persiapan Pelaksanaan PKM, dan Pelaksanaan Program PKM.

\section{Survei Lokasi Kegiatan}

Pada kegiatan ini, dilakukan survei lokasi kegiatan untuk mengetahui kondisi kawasan mangrove serta kondisi sosial budaya masyarakat setempat. Kegiatan survei lokasi dilakukan dengan cara meninjau kondisi kawasan mangrove di Labu Sawo dan mendata fasilitas yang sudah tersedia yang nantinya dapat mendukung kegiatan ekowisata mangrove. Selain itu, dilakukan pula wawancara dengan masyarakat di Labu Sawo. Pemilihan narasumber untuk kegiatan wawancara menggunakan metode purposive sampling. Beberapa orang yang diwawancarai diantaranya ketua POKDARWIS Labu Sawo dan beberapa anggota masyarakat secara langsung maupun tidak langsung terlibat dalam kegiatan pemanfaatan kawasan mangrove di kawasan tersebut.

\section{Persiapan Pelaksanaan PKM}

Materi kegiatan dibuat sesederhana mungkin dengan disertai contoh-contoh kasus dalam kegiatan pengelolaan kawasan ekowisata. Adapun materi yang disiapkan yaitu Teknik Penilaian Kelayakan Pengembangan Objek Daya Tarik Wisata dan Pengembangan Wisata Alam dalam Kawasan Hutan.

\section{Pelaksanaan Program PKM}

Dalam kegiatan pengabdian mengenai identifikasi potensi ekowisata mangrove ini, pendekatan yang diterapkan dalam kegiatan pengabdian ini adalah metode penyelesaian masalah. Penyelesaian masalah ini meliputi:

1. Mengidentifikasi potensi-potensi lokal yang dapat dikembangkan untuk meningkatkan perekonomian masyarakat lokal yang sejalan dengan upaya pengelolaan kawasan mangrove.

2. Memberikan penyuluhan mengenai strategi pengelolaan kawasan mangrove yang dapat menopang perekonomian masyarakat setempat,

Dengan demikian, materi kegiatan yang disampaikan dalam kegiatan ini yaitu:

1. Teknik Penilaian Kelayakan Pengembangan Objek Daya Tarik Wisata (Departemen Kehutanan, 2003) 
Penyampaian materi mengenai Teknik Penilaian Kelayakan Pengembangan Objek Daya Tarik Wisata dilakukan dengan membentuk focus group disscussion (FGD) kecil. Banyak hal yang didiskusikan dalam tahap ini, misalnya potensi apa saja yang dimiliki oleh Dusun Labu Sawo yang nantinya dapat menunjang perkembangan kawasan ekowisata mangrove.

2. Upaya Pengembangan Wisata Alam dalam Kawasan Hutan.

Kegiatan penyampaian materi dilaksanakan dengan menggunakan metode Pendidikan Orang Dewasa (POD) dengan penekanan pada model komunikasi dua arah dengan pola tukar menukar pengalaman, diskusi kelompok, dan demonstrasi yang dilaksanakan dalam bentuk klasikal. Materi ini diawali dengan menjelaskan kepada peserta PKM mengenai manfaat mangrove baik secara ekologis maupun secara ekonomis.

\section{HASIL DAN PEMBAHASAN}

Berdasarkan hasil survei lokasi kegiatan, diketahui bahwa kondisi kawasan mangrove masih sangat bagus. Mangrove di sini merupakan tempat hidup bagi kelelawar dan monyet yang dapat dijadikan obyek wisata.

Selain itu, kondisi sosial terkait tingkat pendidikan menunjukkan bahwa tidak banyak masyarakat yang mengenyam pendidikan tinggi. Walaupun demikian, di kawasan ini budaya masyarakat dapat menjadi daya tarik bagi wisatawan. Terdapat atraksi pacuan kuda yang rutin dilaksanakan dengan tujuan untuk menghibur masyarakat setempat.

Pelaksanaan kegiatan pengabdian ini dirasakan sangat bermanfaat bagi para peserta. Hal ini diketahui dari komentar (pesan dan kesan) para peserta yang dikumpulkan pasca kegiatan penyampaian materi serta diskusi yang dibangun dalam kegiatan ini.

Dalam kegiatan pengabdian ini, peserta kegiatan juga membuka permasalahan yang selama ini dihadapi POKDARWIS terkait dengan upaya pengelolaan ekowisata mangrove di Labu Sawo. Adapun manfaat mangrove yang selama ini diketahui oleh masyarakat lokal terbatas pada fungsi mangrove sebagai penahan gelombang dari laut atau gelombang tsunami. Akan tetapi manfaat lain mangrove yaitu sebagai perangkap sedimen yang berasal dari sungai serta memperlambat erosi; pengurai limbah organik yang terbawa ke wilayah pantai; membantu intrusi air laut ke daratan; serta penyimpan karbon yang berasal dari atmosfer belum banyak diketahui oleh masyarakat lokal.

Pemerintah daerah saat ini telah menginisiasi pengembangan kawasan ekowisata mangrove Labu Sawo. Beberapa upaya yang telah dilakukan oleh pemerintah daerah yaitu memfasilitasi pembuatan trekking serta membentuk POKDARWIS yang diberikan wewenang untuk mengelola kawasan ini.

Sementara itu, hasil dari kegiatan penilaian kelayakan pengembangan obyek wisata yang mengacu pada Teknik Pedoman Analisis Daerah Operasi dan Daya Tarik Wisata oleh Direktorat Jenderal PHKA Tahun 2003, menunjukkan bahwa terdapat beberapa parameter yang masuk dalam kriteria penilaian.

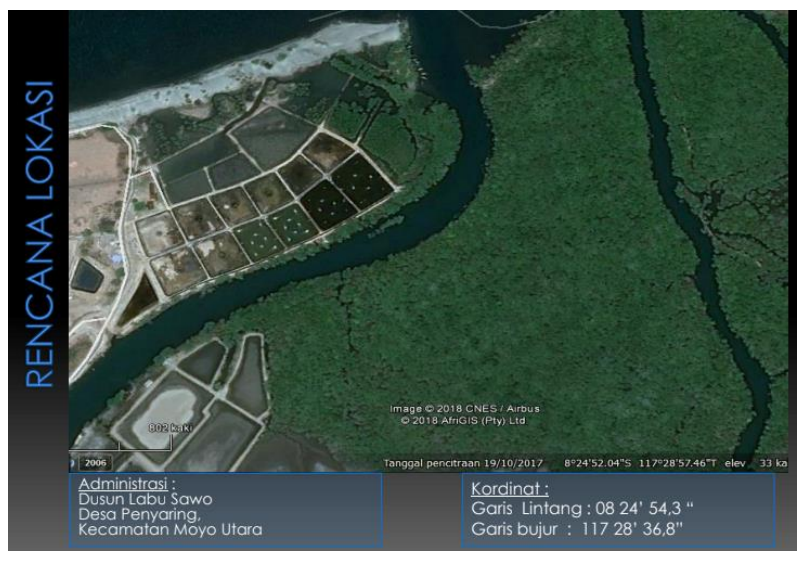

Gambar 1. Rencana Lokasi Pengembangan Kawasan Ekowisata Mangrove Labu Sawo, Desa Penyaring, Kabupaten Sumbawa, NTB

Parameter-parameter yang masuk dalam kriteria penilaian kelayakan pengembangan obyek wisata yang dimiliki oleh kawasan ekowisata mangrove Labu Sawo antara lain:

1. Keunikan sumberdaya alam yang dimiliki yaitu adanya flora (mangrove), fauna (kelelawar), adat budaya (seni tari, barapan kerbau), serta sungai yang membatasi kawasan mangrove dengan pemukiman penduduk. Parameter ini memperoleh skor 150 .

2. Kegiatan yang dapat dilakukan pengunjung meliputi menikmati keindahan alam, melihat 
flora dan fauna, trekking (yang sudah dibuat dengan difasilitasi oleh pemerintah daerah sepanjang kurang lebih 300 meter), dan penelitian/pengabdian (potensial obyek yaitu flora dan fauna di dalam kawasan mangrove). Parameter ini memperoleh skor 150.

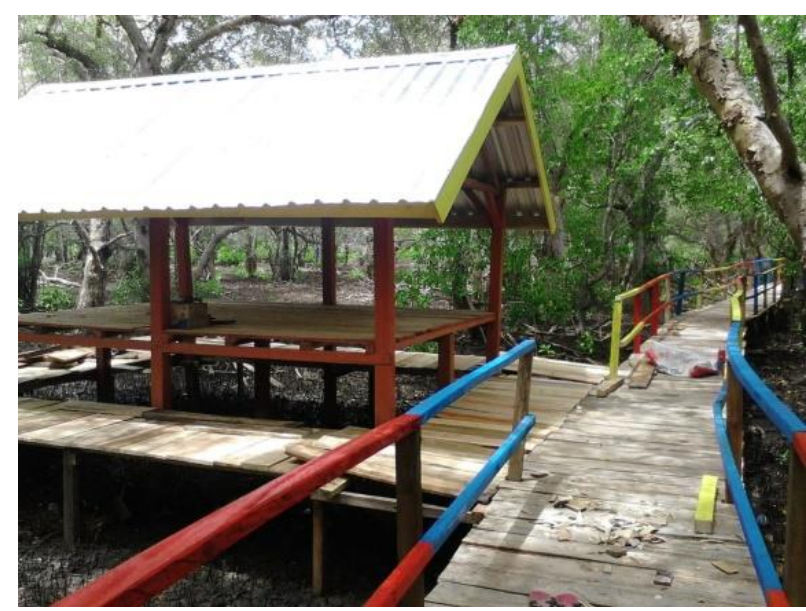

Gambar 2. Trekking di dalam Kawasan Mangrove Labu Sawo

3. Kebersihan lokasi obyek wisata meliputi adanya pemukiman penduduk dan sampah. Parameter ini memperoleh skor 150.

4. Kemanan kawasan di lokasi ini sangat baik karena tidak ditemukan kriteria kriteria seperti arus berbahaya, pertambangan dan penebangan liar, pencurian, penyakit yang berbahaya, kepercayaan yang mengganggu, serta tanah longsor. Parameter ini memperoleh skor 180.

5. Kenyamanan di lokasi ini meliputi udara yang bersih dan sejuk, bebas dari bau yang mengganggu, bebas dari kebisingan, serta tidak ada lalu lintas yang mengganggu, Parameter ini memperoleh skor 150.

6. Aksesibilitas dan kondisi jalan menuju kawasan ini termasuk dalam kriteria sedang. Walaupun demikian, tidak sulit untuk mencapai lokasi ini bahkan untuk kendaraan roda empat. Parameter ini memperoleh skor 100.

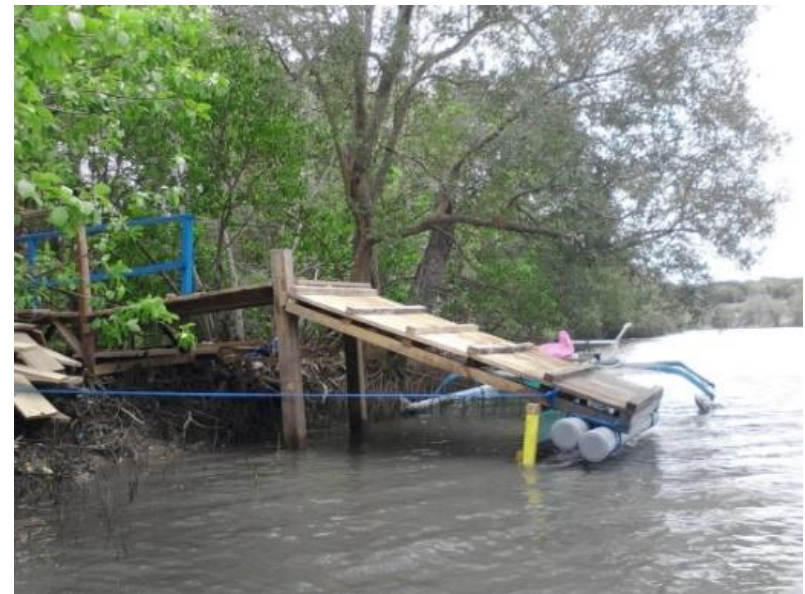

Gambar 3. Dermaga menuju Kawasan Mangrove

7. Akomodasi penginapan di kawasan ini belum ada sehingga parameter ini memperoleh skor 30.

8. Sarana dan prasarana yang memadai seperti rumah makan, transportasi, toko cinderamata, anjungan tunai mandiri, serta pusat perbelanjaan belum ditemukan di sekitar kawasan ekowisata mangrove Labu Sawo. Parameter ini memperoleh skor 30.

Adapun total skor adalah 940 dari total maksimal skor 1290.

Indeks kelayakan $=$ total skor/skor maksimal x 100\%

$=940 / 1290 \times 100 \%$

$$
=72,8 \%
$$

Dengan demikian, kawasan ini memiliki indeks kelayakan sebesar 72,8\% atau Indeks > $66,6 \%$ (Direktorat Jenderal PHKA, 2003) yang berarti kawasan ekowisata ini sangat layak untuk dikembangkan.

Pada dasarnya pengembangan perekonomian di kawasan ekowisata sangat membutuhkan dukungan sarana dan prasarana. Walaupun demikian, kelak pembangunan seluruh fasilitas seperti penginapan, toko cinderamata, Anjungan Tunai Mandiri (ATM), serta rumah makan harus difikirkan dengan baik agar tidak mengganggu keaslian kondisi dari kawasan yang akan dijadikan obyek wisata. Hal ini dibutuhkan untuk menjaga keberlanjutan keberadaan obyek wisata tersebut serta daya tarik dari kawasan mangrove tersebut.

Oleh karena itu, kemungkinan pengembangan perekonomian masyarakat lokal diarahkan ke luar kawasan mangrove. Salah satu lokasi yang memungkinkan yaitu lokasi yang 
berdekatan dengan lokasi pacuan kuda yang berjarak kurang lebih $2 \mathrm{~km}$ dari lokasi penyeberangan ke kawasan ekowisata mangrove.

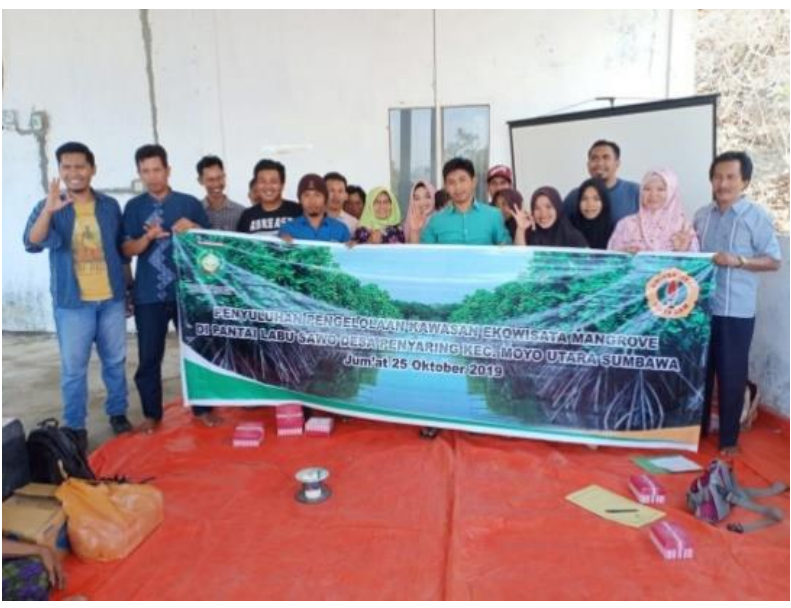

Gambar 4. Peserta Kegiatan PKM

Dusun Labu Sawo ini terdapat atraksi pacuan kuda yang memiliki nilai jual. Walaupun demikian, pengelolaan kegiatan ini perlu dimaksimalkan antara lain dengan cara meningkatkan publikasi mengenai atraksi ini, membuat jadwal tetap atraksi yang dapat dijadikan acuan bagi para pengunjung yang akan datang ke tempat ini.

Selain atraksi pacuan kuda, beberapa usaha lokal yang sudah ada seperti produksi permen susu dan bandeng presto yang merupakan industri rumah tangga juga perlu difasilitasi terutama dalam hal branding dan marketing. Hal ini diperlukan untuk meningkatkan harga jual produk lokal sehingga secara tidak langsung dapat meningkatkan penghasilan para pelaku industri rumah tangga setempat.

Dalam upaya pengelolaan kawasan ekowisata mangrove ini, sangat diperlukan dukungan dari pemerintah daerah serta masyarakat lokal. Pelatihan-pelatihan dalam rangka meningkatkan kapasitas dan kualitas sumber daya manusia sangat penting untuk menunjang pengembangan kawasan ini. Selain itu, strategi pengembangan dan pengelolaan yang tepat harus dirumuskan lebih lanjut agar tidak mengorbankan kawasan mangrove sebagai salah satu objek yang akan dikunjungi oleh para wisatawan.

\section{KESIMPULAN DAN SARAN}

Berdasarkan hasil kegiatan Pengabdian pada Masyarakat yang dilakukan di Dusun Labu Sawo, Desa Penyaring, Kabupaten Sumbawa, dapat disimpulkan bahwa:

1. Kawasan mangrove Dusun Labu Sawo layak untuk dikembangkan menjadi kawasan ekowisata.

2. Pokdarwis sebagai peserta kegiatan sudah memiliki gambaran mengenai potensi serta arah pengembangan kawasan ekowisata mangrove.

\section{UCAPAN TERIMAKASIH}

Tim pelaksana PKM mengucapkan terimakasih kepada Dinas Lingkungan Hidup Kabupaten Sumbawa yang telah memfasilitasi pelaksanaan kegiatan pengabdian ini. Ucapan terima kasih juga disampaikan kepada POKDARWIS Labu Sawo atas partisipasinya serta GAIA (LSM) atas dukungannya dalam kegiatan ini.

\section{DAFTAR PUSTAKA}

Departemen Kehutanan. (2003). Pedoman Analisis Daerah Operasi Objek Daya Tarik Wisata Alam. Direktorat Wisata Alam dan Pemanfaatan Jasa Lingkungan, Direktorat Jenderal Perlindungan Hutan dan Konservasi Alam. Bogor: Departemen Kehutanan RI.

Halidah, H., Saprudin, S. \& Anwar. C. (2008). Potensi dan Ragam Pemanfaatan Mangrove untuk Pengelolaannya di Sinjai Timur, Sulawesi Selatan. Jurnal Penelitian Hutan dan Konservasi Alam, Vol 5 (1). Diambil dari http://ejournal.forda-mof.org/ejournallitbang/index.php/JPHKA/article/view/1141

TIES. (2014). The International Ecotourism Society. Ecolodge. Didownload dari https://ecotourism.org/our-story/

Umayah, S., Gunawan, H. \& Isda, M. N. (2016). Tingkat Kerusakan Ekosistem Mnagrove di Desa Teluk Belitung Kecamatan Merbau Kabupaten Kepulauan Meranti. Jurnal Riau Biologia, Vol 1 (1). Diambil dari https://ejournal.unri.ac.id/index.php/JRB/ar ticle/view/3301 